\title{
Paravalvular leak, the Achilles' heel of valve replacement: Will transcatheter techniques be the answer?
}

Sameh M. Said, MD

See related article on pages $1270-5$.

Despite the advances in valve replacement techniques, periprosthetic regurgitation or paravalvular leak (PVL) continues to be a serious problem that leads to an increase in morbidity and mortality. The reported incidences are about $7 \%$ to $17 \%$ in mitral valve replacement and $2 \%$ to $10 \%$ in aortic valve replacement. ${ }^{1}$ Several known risk factors have been associated with PVL, such as severe annular calcifications, endocarditis, and tissue friability. Patients may be seen with heart failure, symptomatic hemolysis, or both. ${ }^{2}$ Options for treatment include both reoperation and transcatheter techniques.

The literature is rich with case reports and retrospective studies about the use of device closure for PVL, which is currently being performed off label; however, very little has been published on surgical outcomes.

In their current study published in this issue of the Jour$n a l$, Taramasso and colleagues ${ }^{3}$ address the issue of PVL in relation to both mitral and aortic prostheses. This retrospective study included 122 consecutive patients ( 82 with mitral PVL and 40 with aortic PVL) who underwent reoperation for symptomatic PVL. The mean age was $62 \pm 11$ years. Symptomatic hemolysis was present in $31 \%$ of the patients, and most of these patients $(60 \%)$ were in New York Heart Association class III or IV, which is not unusual for this group of patients who have been followed up for a long time with their PVL. Repair of the PVL was feasible in most cases ( 79 patients, or $65 \%$ ), whereas reoperative replacement was needed in the remaining cases (43 patients, or $35 \%)$. The early mortality was high $(10.7 \%)$, and it was even higher for the mitral prostheses than for the aortic prostheses (13\% for mitral PVL vs $5 \%$ for aortic PVL). Multivariate analysis identified preoperative chronic renal failure and more than 1 previous cardiac reoperation as risk factors for late mortality. Taramasso and colleagues ${ }^{3}$

From the Division of Cardiothoracic Surgery, Lucile Packard Children's Hospital, Stanford, Calif.

Disclosures: Author has nothing to disclose with regard to commercial support.

Received for publication Jan 8, 2015; accepted for publication Jan 8, 2015; available ahead of print Feb 11, 2015.

Address for reprints: Sameh M. Said, MD, Division of Cardiothoracic Surgery, Lucile Packard Children's Hospital, Stanford, CA 94305 (E-mail: smsaid75@yahoo. com).

J Thorac Cardiovasc Surg 2015;149:1276-7

0022-5223/\$36.00

Copyright (c) 2015 by The American Association for Thoracic Surgery

http://dx.doi.org/10.1016/j.jtcvs.2015.01.015 concluded that these results support the importance of alternative therapeutic options.

Several points are worth attention:

1. The alternative treatment option to which Taramasso and colleagues ${ }^{3}$ refer is probably transcatheter techniques, but are these really the answer? In looking at 1 of the 2 largest series for device

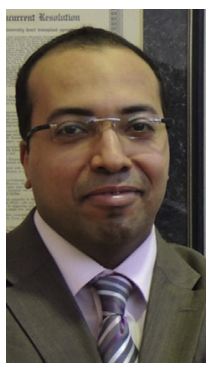
closure of PVL, which comes from the Mayo Clinic ${ }^{4}$ and includes 30-day outcomes of 115 patients, the technique was successful only in $77 \%$ of the patients, and $15 \%$ of the patients had multiple defects. The study had 3-year follow-up data, and the surprising findings were that there were no differences in survival according to the degree of residual regurgitation, even if it was severe, and that hemolytic anemia was difficult to resolve among survivors and was an independent predictor for poor survival and need for cardiac surgery.

2. It remains unclear which group is better referred for surgery and which is better served by device closure.

3. Are the indications for reoperation based on the presence of symptoms, or should these patients be referred earlier for surgery even if they are free of symptoms?

4. What is to be done with multiple leaks?

5. What about patients who have repeat PVL? This group exists, and their management represents a clinical dilemma with no clear answer.

6. Finally, what were the outcomes of patients who had failure of device closure and had to undergo reoperation? They may be worse; we don't know.

The concept of considering most PVL as being benign may not be entirely accurate and only results in delaying interventions. And this starts with proper evaluation, which may require combination of imaging modalities such as echocardiography, magnetic resonance imaging, and angiography, especially in cases where there is discrepancy in the assessment.

But does the degree of PVL really matter? Or does the mere presence of a leak mandate intervention? In recent data from the Placement of Aortic Transcatheter Valves (PARTNER) trial, even mild PVL was associated with a significant risk of mortality. ${ }^{5}$ Should we apply the same principle in relation to conventional valve replacement?

The same group of authors has previously compared conventional surgery and transcatheter closure of PVL. ${ }^{6}$ They reported 98\% acute procedural success and 9.3\% in-hospital mortality in the surgical group, versus no deaths 
in the transcatheter group. But were the groups really equal? They also reported less than moderate residual valve regurgitation in all patients, but is this how we define success?

There is no doubt that this is a high-risk group of patients often referred late for surgery because of the fear of reoperation. By the time of reoperation, however, the patient has severe symptoms or is in an advanced stage of heart failure, which results in bad outcomes.

The use of percutaneous techniques seem to be promising for this sick group of patients and will continue to evolve; however it is important to have certain standards and clear goals. We need to define success with strict criteria and not only the mere reduction of PVL.

The bottom line is that PVL should be aggressively addressed, and to ensure good outcomes, referral of the patient to the surgeon should not be delayed.

\section{References}

1. McElhinney DB. Will there ever be a Food and Drug Administration-approved device for transcatheter paravalvular leak closure? Circ Cardiovasc Interv. 2014; $7: 2-5$

2. Gössl M, Rihal CS. Percutaneous treatment of aortic and mitral valve paravalvular regurgitation. Curr Cardiol Rep. 2013;15:388.

3. Taramasso M, Maisano F, Denti P, Guidotti A, Sticchi A, Pozzoli A, et al Surgical treatment of paravalvular leak: long-term results in a single-center experience (up to 14 years). J Thorac Cardiovasc Surg. 2015;149:1270-5.

4. Sorajja P, Cabalka AK, Hagler DJ, Rihal CS. Long-term follow up of percutaneous repair of paravalvular prosthetic regurgitation. J Am Coll Cardiol. 2011;58: 2218-24.

5. Kodali SK, Williams MR, Smith CR, Svensson LG, Webb JG, Makkar RR, et al; PARTNER Trial Investigators. Two-year outcomes after transcatheter or surgical aortic-valve replacement. N Engl J Med. 2012; 366:1686-95.

6. Taramasso M, Maisano F, Latib A, Denti P, Guidotti A, Sticchi A, et al. Conventional surgery and transcatheter closure via surgical transapical approach for paravalvular leak repair in high-risk patients: results from a single-centre experience. Eur Heart J Cardiovasc Imaging. 2014;15:1161-7. 